\title{
Structural, Optical, and Magnetic Properties of $\mathrm{NiMoO}_{4}$ Nanorods Prepared by Microwave Sintering
}

\author{
Ana P. de Moura, ${ }^{1}$ Larissa H. de Oliveira, ${ }^{1}$ Ieda L. V. Rosa, ${ }^{2}$ \\ Camila S. Xavier, ${ }^{1}$ Paulo N. Lisboa-Filho, ${ }^{3}$ Máximo S. Li, ${ }^{4}$ Felipe A. La Porta, ${ }^{1,2}$ \\ Elson Longo, ${ }^{1}$ and José A. Varela ${ }^{1}$ \\ ${ }^{1}$ Instituto de Química, UNESP, 14800-900 Araraquara, SP, Brazil \\ ${ }^{2}$ Departamento de Química, UFSCar, 13565-905 São Carlos, SP, Brazil \\ ${ }^{3}$ Departamento de Física, UNESP, 13565-905 Bauru, SP, Brazil \\ ${ }^{4}$ Departamento de Física, USP, 13560-970 São Carlos, SP, Brazil \\ Correspondence should be addressed to Felipe A. La Porta; felipe_laporta@yahoo.com.br
}

Received 29 August 2014; Accepted 4 December 2014

Academic Editor: Ching-Fuh Lin

Copyright (C) 2015 Ana P. de Moura et al. This is an open access article distributed under the Creative Commons Attribution License, which permits unrestricted use, distribution, and reproduction in any medium, provided the original work is properly cited.

\begin{abstract}
We report on the structural, optical, and magnetic properties of $\alpha, \beta-\mathrm{NiMoO}_{4}$ nanorods synthesized by annealing the $\mathrm{NiMoO}_{4}: n \mathrm{H}_{2} \mathrm{O}$ precursor at $600^{\circ} \mathrm{C}$ for 10 minutes in a domestic microwave. The crystalline structure properties of $\alpha, \beta-\mathrm{NiMoO}_{4}$ were investigated using X-ray diffraction (XRD), Fourier transform infrared (FTIR), and Raman (FT-Raman) spectroscopies. The particle morphologies and size distributions were identified by field emission microscopy (FE-SEM). Experimental data were obtained by magnetization measurements for different applied magnetic fields. Optical properties were analyzed by ultravioletvisible (UV-vis) and photoluminescence (PL) measurements. Our results revealed that the oxygen atoms occupy different positions and are very disturbed in the lattice and exhibit a particular characteristic related to differences in the length of the chemical bonds (Ni-O and Mo-O) of the cluster structure or defect densities in the crystalline $\alpha, \beta-\mathrm{NiMoO}_{4}$ nanorods, which are the key to a deeper understanding of the exploitable physical and chemical properties in this study.
\end{abstract}

\section{Introduction}

Over the past few decades, morphology as well as size control of crystalline materials is the key requirement for their industrial exploitation with unprecedented capabilities in emerging technologies [1-4]. In this context, nickel molybdates $\left(\mathrm{NiMoO}_{4}\right)$ have received much attention, due to their remarkable record of widespread applications in different fields of materials science, such as photocatalysis, phosphors, light-emitting diodes, optical fibers, humidity sensors, scintillators, and magnetic properties [5]. Under atmospheric pressure, three compounds of $\mathrm{NiMoO}_{4}$ are known: the low temperature $\alpha$-phase, the high temperature $\beta$-isomorph, and the hydrate and $\mathrm{NiMoO}_{4}: n \mathrm{H}_{2} \mathrm{O}$, respectively [6-10]. Both $\alpha$ $\mathrm{NiMoO}_{4}$ and $\beta-\mathrm{NiMoO}_{4}$ are often obtained by heating their nickel molybdate hydrates $\mathrm{NiMoO}_{4}: n \mathrm{H}_{2} \mathrm{O}$ that is utilized as a precursor [11]. On the other hand, the synthesis of the pure $\beta$ $\mathrm{NiMoO}_{4}$ phase is usually generated by heating the $\alpha-\mathrm{NiMoO}_{4}$ at temperature above $760^{\circ} \mathrm{C}$; however, the $\beta-\mathrm{NiMoO}_{4}$ phase is stable only above $180^{\circ} \mathrm{C}$ due that on cooling below at this temperature transforms again into the $\alpha-\mathrm{NiMoO}_{4}$ phase, which is more stable under these conditions [12-15]. These studies have examined the catalytic properties of both phases and in all these cases the $\beta-\mathrm{NiMoO}_{4}$ phase showed a higher efficiency in these tests. However, very little has been reported on the optical properties of these systems.

It has been known that preparation and conditions methods become essential to control the obtention of semiconductor nanomaterials with the tunable physical and chemical properties, which are very important in a wide range of applications in nanotechnology [16-18]. Recently, the domestic microwave oven has been successfully employed to obtain 


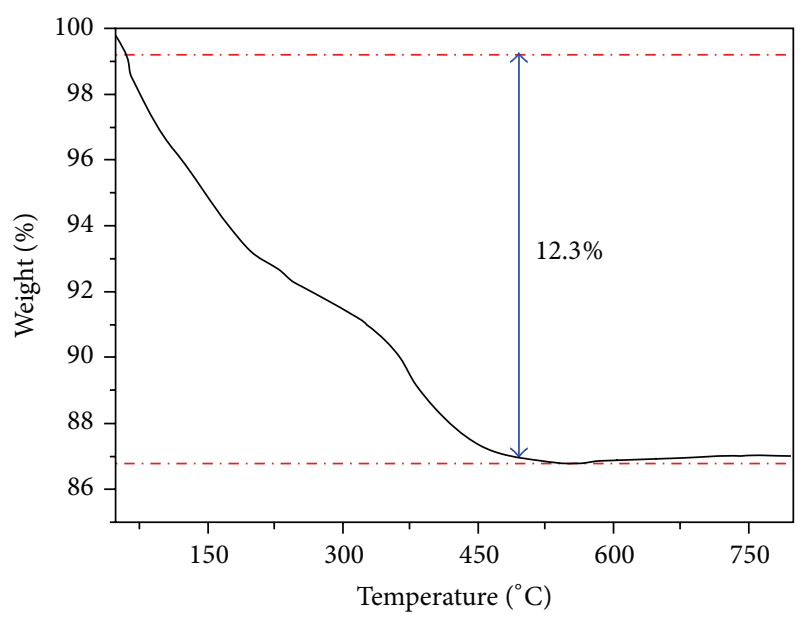

Figure 1: TGA curve of the precursor $\mathrm{NiMoO}_{4} \cdot n \mathrm{H}_{2} \mathrm{O}$.

many ceramic materials with improved quality and size distributions of the nanomaterials [19-22]. Advantages such as rapid heating, selective material coupling, and enhanced reaction kinetics make the microwave process an attractive route for these materials' synthesis [23-27], showing significant advantages against conventional sintering procedures [28-30]. Recently, Oghbaei and Mirzaee [30] reported a complete review on the subject.

Therefore, in this work, we report the correlation among optical and magnetic properties of the $\alpha, \beta-\mathrm{NiMoO}_{4}$ nanorods synthesized by annealing the $\mathrm{NiMoO}_{4}: n \mathrm{H}_{2} \mathrm{O}$ precursor at $600^{\circ} \mathrm{C}$ for 10 minutes in a domestic microwave. Moreover, these nanorods were analyzed by XRD, FTIR, FT-Raman, FE-SEM, UV-vis, and PL, and magnetic behavior was also studied. In this context, the structural and electronic orderdisorder effects influence physical properties as it will be shown here. In addition, the effects, as well as the influence, of microwave heating by using the synthetic process are reported.

\section{Materials and Methods}

2.1. Synthesis of $\alpha, \beta-\mathrm{NiMoO}_{4}$ Powders. In a typical procedure, $2 \mathrm{mmol}$ of sodium molybdate solution was dissolved in $50 \mathrm{~mL}$ of distilled water. Afterwards, $2 \mathrm{mmol}$ of nickel nitrate hexahydrate was dissolved in $50 \mathrm{~mL}$ of deionized water, which was slowly added into the sodium molybdate solution under magnetic stirring giving rise to a homogeneous solution $(\mathrm{pH}=6)$. The reactional mixture was put under magnetic stirring during 30 minutes. Then, the obtained precipitate was water washed for several times, and the powder of green-yellow color was dried at $60^{\circ} \mathrm{C}$ for 12 hours under air atmosphere in a conventional furnace. The obtained precursor was investigated using thermal analysis. Figure 1 shows the TGA curve for the thermal decomposition of the precursor. TGA curves of the $\mathrm{NiMoO}_{4} \cdot n \mathrm{H}_{2} \mathrm{O}$ samples with the temperature ranging from 30 to $800^{\circ} \mathrm{C}$ show that a mass losses at about $480 \circ \mathrm{C}$ was $12.3 \%$ in the net weight, mainly ascribed to the loss of water content in the $\mathrm{NiMoO}_{4} \cdot n \mathrm{H}_{2} \mathrm{O}$.
Therefore we choose $600^{\circ} \mathrm{C}$ as the heating temperature to obtain the $\alpha, \beta-\mathrm{NiMoO}_{4}$ nanorods. The $\alpha, \beta-\mathrm{NiMoO}_{4}$ yellowlike powders were obtained from thermal decomposition of the precursor powders in ceramic crucibles and heated in a microwave sintering furnace at $600^{\circ} \mathrm{C}$ for 10 minutes.

2.2. Characterizations. The powders were characterized by $\mathrm{X}$-ray diffraction (XRD) using a Rigaku-DMax $2500 \mathrm{PC}$, Japan, with $\mathrm{Cu} \mathrm{K} \alpha$ radiation $(\lambda=1.540598 \AA)$ in the $2 \theta$ range from $10^{\circ}$ to $75^{\circ}$ using a scanning rate of $0.02^{\circ} / \mathrm{min}$. The phase analysis by the Rietveld and Le Bail method [31, 32] was carried out using the General Structure Analysis System (GSAS) software [33]. FT-IR spectroscopies were performed in the range from 400 to $4000 \mathrm{~cm}^{-1}$, using a Bruker-Equinox 55 (Germany) spectrometer in transmittance mode. FTRaman spectroscopy was recorded with a Bruker-RFS 100 (Germany). The spectra were obtained using a $1064 \mathrm{~nm}$ line of Nd:YAG laser, keeping its maximum output power at $110 \mathrm{~mW}$.

The morphologies of the samples were verified using a field emission gun scanning electron microscopy (Jeol JSM 6330F). UV-vis spectra were taken using Cary 5G (Varian, USA) equipment in the diffuse reflection mode. The thermal decomposition of the precursor powders was studied by thermogravimetric analysis (TGA/DTA) on a TGA2050 thermal analysis device (American TA Corporation). TGA determination was carried out in air at a heating rate of $20^{\circ} \mathrm{C} \mathrm{min}^{-1}$ in the range from room temperature to $900^{\circ} \mathrm{C}$.

The PL measurements were taken in a Thermal JarrelAsh Monospec 27 monochromator and a Hamamatsu R446 photomultiplier. The $350.7 \mathrm{~nm}$ exciting wavelength of a krypton ion laser (Coherent Innova) was used with the nominal output power of the laser power kept at $200 \mathrm{~mW}$. All the measurements were taken at room temperature. Magnetization versus an applied field in a zero field cooled (ZFC) and field cooled (FC) measurements was performed using a Quantum Design Magnetic Properties Measurement System (MPMS) XL-5 Superconducting Quantum Interference Device.

\section{Results and Discussion}

The crystallinity and crystal structures of the precursor and calcined products $\left(\alpha\right.$ - and $\left.\beta-\mathrm{NiMoO}_{4}\right)$ were examined by $\mathrm{X}$ ray diffraction (XRD) as shown in Figure 2(a). The precursor composition is mainly associated with the hydrate precursor. This conclusion was possible, since the diffractograms present the characteristic peaks of this matrix according to JCPDS data file number 13-0128 [34]. In the XRD pattern of the precursor calcined all the reflectance peaks can be perfectly indexed to the mixture of the $\alpha-\mathrm{NiMoO}_{4}$ and $\beta$ $\mathrm{NiMoO}_{4}$ phases that it was possible to identify the presence of intense well defined and sharp diffraction peaks, which are characteristics of solids structurally ordered in a long-range, according to the JCPDS data file numbers 33-948 and 12348 , respectively. Under these conditions we can see that the sample is richer in the $\alpha-\mathrm{NiMoO}_{4}$ phase. This conclusion is in line with previous work of other groups [34-37].

From the structural point of view, $\alpha-\mathrm{NiMoO}_{4}$ and $\beta$ $\mathrm{NiMoO}_{4}$ phases have a monoclinic crystal structure (group 


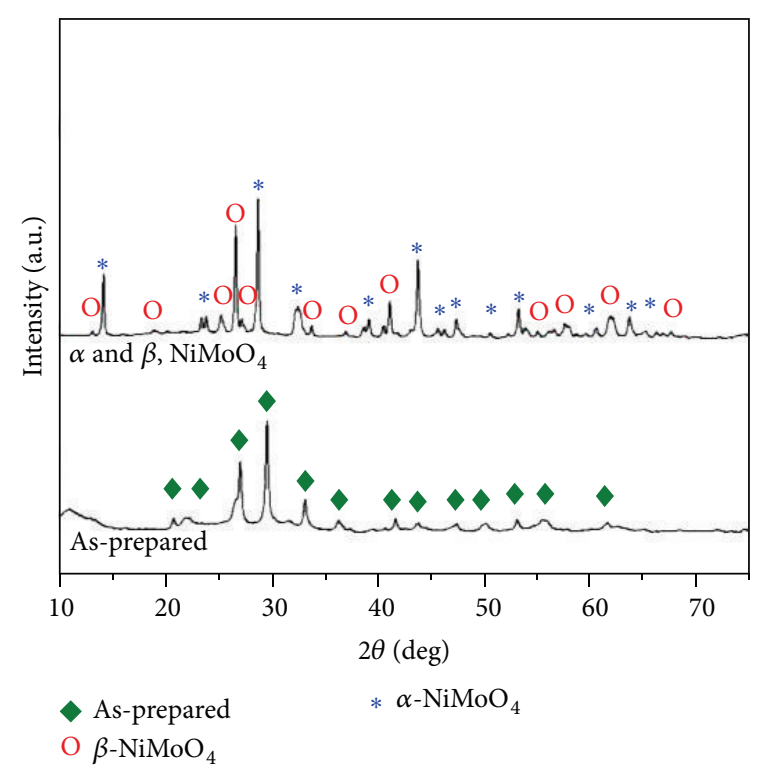

(a)

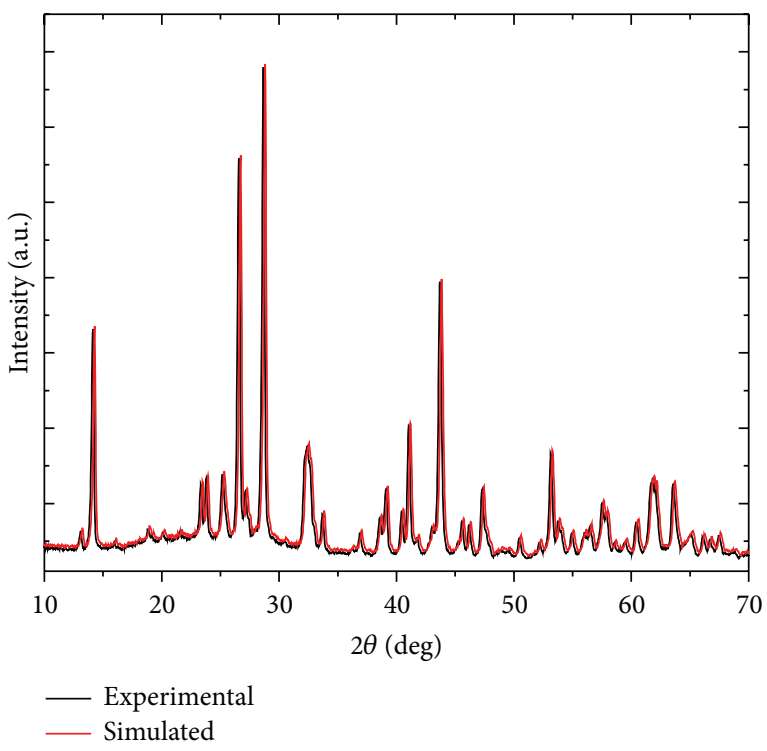

(b)

FIGURE 2: (a) XRD patterns of the as-prepared powder and the powders heated at $600^{\circ} \mathrm{C}$ for 10 minutes in a microwave oven together with (b) structural refinements plot for the $\alpha, \beta-\mathrm{NiMoO}_{4}$ nanostructures.

space $\mathrm{C} 12 / \mathrm{ml}$ ) and the most important differences between both phases are different coordination for the molybdenum ions in the crystal structure, being octahedral cluster, $\left[\mathrm{MoO}_{6}\right]$, for the $\alpha-\mathrm{NiMoO}_{4}$ and tetrahedral one, $\left[\mathrm{MoO}_{4}\right]$, for the $\beta-\mathrm{NiMoO}_{4}$ powder [30]. In order to analyze and understand whether there are differences in the structural arrangements of both phases in the sample calcined at $600^{\circ} \mathrm{C}$ for 10 minutes in a domestic microwave, the Rietveld and Le Bail refinement method was employed (see Figure 2(b)). In particular, the Rietveld method is generally restricted to crystalline phases for which structures are well known allowing the quantification of the phase mixtures [38]. However, for the $\beta-\mathrm{NiMoO}_{4}$ phase these parameters are not very well known. In this context, the Le Bail method is very similar to the Rietveld method, except that in this method there is no need to make the crystal structure refinement, and allowing an adjustment that can be obtained by the integrated intensity and the positions of all peaks in the XRD profile $[32,39]$, and this strategy was used here for the structural determination of the $\beta-\mathrm{NiMoO}_{4}$ phase. In this respect, during the XRD refinements the structural parameters such as scale factor, background with exponential shift, microstructure, crystal structure, shift lattice constants, profile half-width parameters $(u, v, w)$, lattice parameters, texture, factor occupancy, and atomic site occupancies were optimized using the GSAS program [33]. The XRD refinement results of the unit cell parameters are $a=9.602 \AA, b=8.769 \AA, c=7.665 \AA$, and $\beta$ $=114.24 \circ$ for $\alpha-\mathrm{NiMoO}_{4}$, while $a=10.094 \AA, b=9.203 \AA, c=$ $6.996 \AA$, and $\beta=107.17^{\circ}$ for $\beta-\mathrm{NiMoO}_{4}$ phases, respectively. Clearly, the difference between the measured and calculated patterns is considered a way to verify the success of the refinement method, as shown in Figure 2(b); however, it is necessary to check values of the fitting parameters for greater control of these results. In general, the criteria depend on the type of structure, in general, are recommended low values of the $\mathrm{Rw}(<10 \%)$ and $\chi^{2}(<2)$ more reliable are the results of the refinement [1]. As can be observed in Figure 2(b), the quality of the XRD refinement was assessed by the values of the fitting parameters $\left(R_{\mathrm{WP}}=4.3 \%, R_{\mathrm{Bragg}}=0.9 \%\right.$, and $\left.\chi^{2}=1.17\right)$ indicating good agreement between refined and observed XRD patterns for the sample calcined at $600^{\circ} \mathrm{C}$ for 10 minutes in a domestic microwave, and it was noted that the refined parameters are very close to those published in the literature by Haetge et al. [35]. However, some variations in the atomic positions related to oxygen atoms were observed while the nickel and molybdenum atoms remain fixed in their positions within the framework. These results indicate the existence of local structural distortions on the $\left[\mathrm{NiO}_{8}\right],\left[\mathrm{MoO}_{4}\right]$, and $\left[\mathrm{MoO}_{6}\right]$ clusters of $\alpha, \beta-\mathrm{NiMoO}_{4}$ nanorods synthesized by annealing the $\mathrm{NiMoO}_{4}: n \mathrm{H}_{2} \mathrm{O}$ precursor at $600^{\circ} \mathrm{C}$ for 10 minutes in a domestic microwave. In this case, the employed strategy provides information on unit cell parameters, so it can not be used for quantification of the phases present in this sample.

Figures 3(a) and 3(b) illustrate the FTIR and FT-Raman spectra for the $\alpha, \beta-\mathrm{NiMoO}_{4}$ powders synthesized via the precursor decomposition. According to the FTIR spectra shown in Figure 3(a), the presence of large bands was observed at $3470 \mathrm{~cm}^{-1}$ and $1622 \mathrm{~cm}^{-1}$, which could be associated with the stretching and flexing modes of the $\mathrm{O}-\mathrm{H}$ linkages from the water molecules adsorbed in the sample surfaces. The bands at 962 and $882 \mathrm{~cm}^{-1}$ can be assigned to the symmetric and antisymmetric stretching of the $\mathrm{Mo}=\mathrm{O}$ linkage and the band at $492 \mathrm{~cm}^{-1}$ could be associated with torsions of the Mo-O-Mo attachment. The bands at 808 and $706 \mathrm{~cm}^{-1}$, however, are assigned to the vibrations of the Mo-O-Ni 


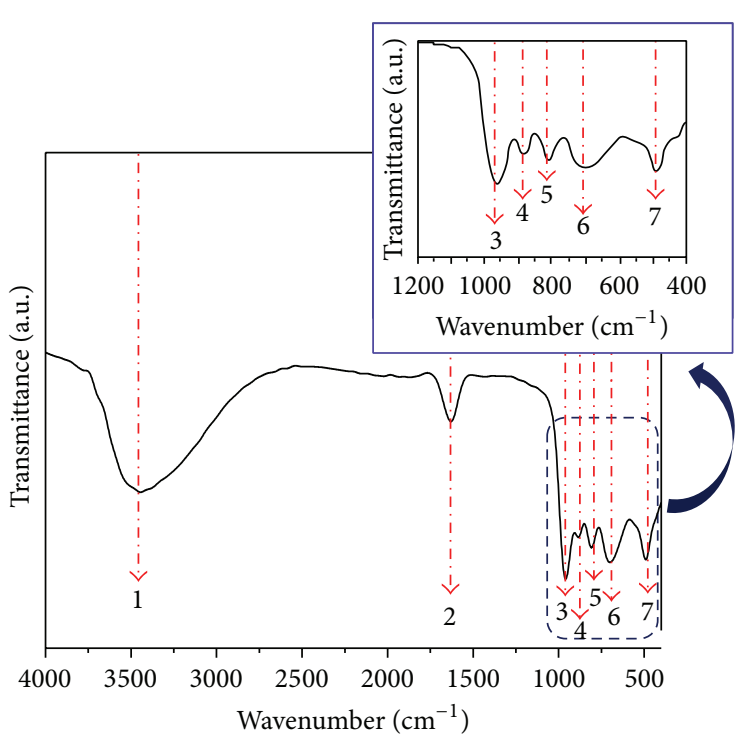

(a)

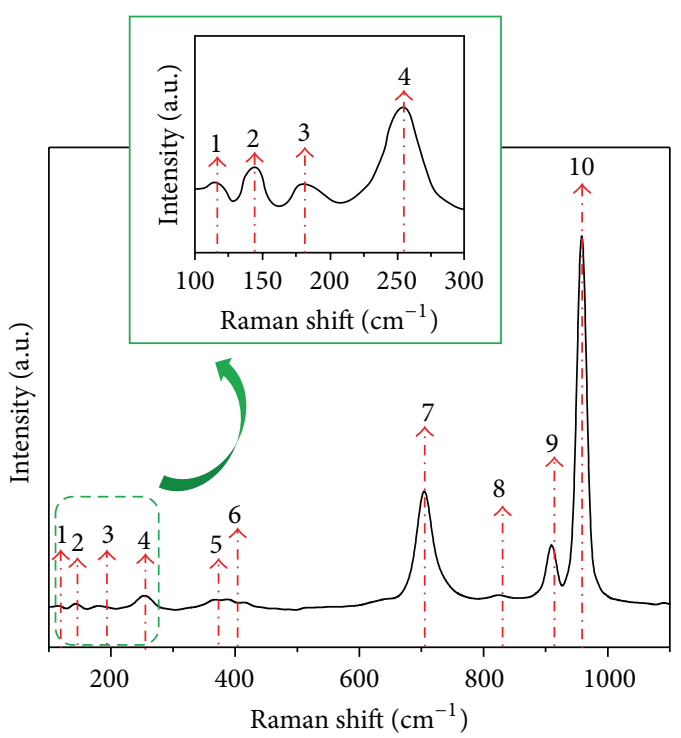

(b)

FIGURE 3: (a) FTIR and (b) FT-Raman spectra of the $\alpha, \beta-\mathrm{NiMoO}_{4}$ nanorods.

(see Figure 3(a)). Figure 3(b) shows the FT-Raman spectra of the $\alpha, \beta-\mathrm{NiMoO}_{4}$ powders indicating that the sample presents structural organization at short range. The results show that the band located at $952 \mathrm{~cm}^{-1}$ is associated with the symmetric stretching mode of Mo-O linkage. The bands at 900 and $826 \mathrm{~cm}^{-1}$ are due to the asymmetric stretching modes of the oxygen in O-Mo-O link. The bands observed at $380 \mathrm{~cm}^{-1}$ and $361 \mathrm{~cm}^{-1}$ are related to the bending modes of asymmetric and symmetric O-Mo-O. The band located at $733 \mathrm{~cm}^{-1}$ is due to the symmetric stretch of the bond Ni-Mo-O. There is also a band at around $261 \mathrm{~cm}^{-1}$ related to deformation modes of Mo-O-Mo linkage. Our results are in very good agreement with other published studies [36, 37, 40, 41].

Representative FE-SEM micrographs were used to study the particle morphologies and size distributions of $\alpha, \beta$ $\mathrm{NiMoO}_{4}$ powders (see Figures $4(\mathrm{a})-4(\mathrm{~d})$ ). In particular, FESEM images show that the synthesis route formed $\alpha, \beta$ $\mathrm{NiMoO}_{4}$ nanorods shape, which corresponds to a polydispersed sample (see Figures 4(a)-4(c)). Figure 4(d) shows the average distribution of the particles width for $\alpha, \beta$ $\mathrm{NiMoO}_{4}$ nanorods. FE-SEM micrographs allowed estimating the average distribution of the particle size for $\alpha$ - and $\beta-\mathrm{NiMoO}_{4}$ powders through the counting of around 100 particles. Figure $4(\mathrm{~d})$ shows the average distribution of the particle width in the range from 25 to $85 \mathrm{~nm}$ for $\alpha, \beta-\mathrm{NiMoO}_{4}$ powders. In this figure, $93 \%$ of the particles presented an average width from 35 to $65 \mathrm{~nm}$. The diameters of the nanorods were determined as $100-300 \mathrm{~nm}$ and the lengths as $1-2 \mu \mathrm{m}$.

Owing the higher surface-to-volume ratio in nanoparticles perform quite differently from the corresponding bulk material [9, 42-44]. Figures 5(a) and 5(b) show the UVvis and PL spectra of the $\alpha, \beta-\mathrm{NiMoO}_{4}$ nanorods. UV-vis diffuse reflectance was used to determine the optical band gap energy of $\alpha, \beta-\mathrm{NiMoO}_{4}$ nanorods (for more details on this methodology see [17]). For our sample, the direct optical band gap presented a value of $\sim 2.15 \mathrm{eV}$, which is in good agreement with values reported in the literature $2.3 \mathrm{eV}$ [45]. The decrease in the band gap value can be attributed to defects and local bond distortion as well as intrinsic surface states and interfaces which yield localized electronic levels within the forbidden band gap [17].

PL emission is considered a powerful tool to obtain information on the electronic structure and degree of structural organization at medium range of the materials [46-49]. The $\mathrm{PL}$ spectrum of the $\alpha, \beta-\mathrm{NiMoO}_{4}$ nanostructures shows a broad band covering a large part of the visible spectrum with a maximum situated at $480 \mathrm{~nm}$ (blue emission), when excited by a $350.7 \mathrm{~nm}$ laser line (see Figure 5). This PL profile suggests an emission mechanism characterized by the participation of several energy levels or light emission centers able to trap electrons within the band gap. To a better understanding of the properties of PL and its dependence on the structural order-disorder of the lattice, the PL curves were analyzed by the PEAKFIT program [50]. The deconvolution results showed that the PL spectrum was better adjusted by four components (P1 - 446 nm, P2 - 493 nm, P3 - 544 nm, and P4 - $606 \mathrm{~nm}$ peak center), and each color represents a different type of electronic transition linked to a specific structural arrangement. The emission band profile is typical of a multiphonon process: that is, a system where relaxation occurs by several paths involving the participation of numerous states within the band gap of the material [46-49].

In previous studies [25, 46-49] we reported that physical behavior for many molybdates compounds having the formula $\mathrm{AMoO}_{4}$, where $\mathrm{A}=\mathrm{Ba}, \mathrm{Ca}, \mathrm{Pb}, \mathrm{Co}$, and $\mathrm{Sr}$, is explained by a model based on defects or distortions in the lattice, that induce to a symmetry break, process in the crystal and favors to the appearance of new intermediate 


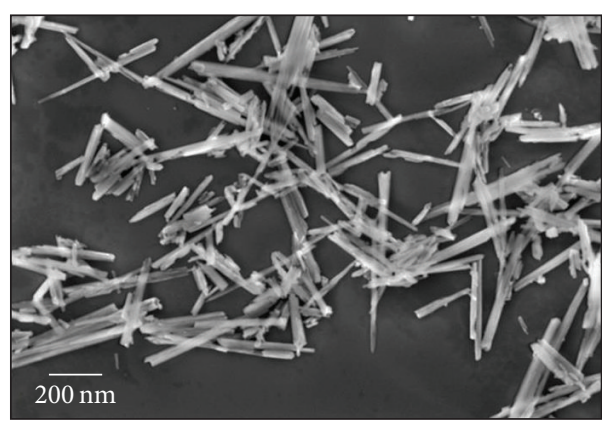

(a)

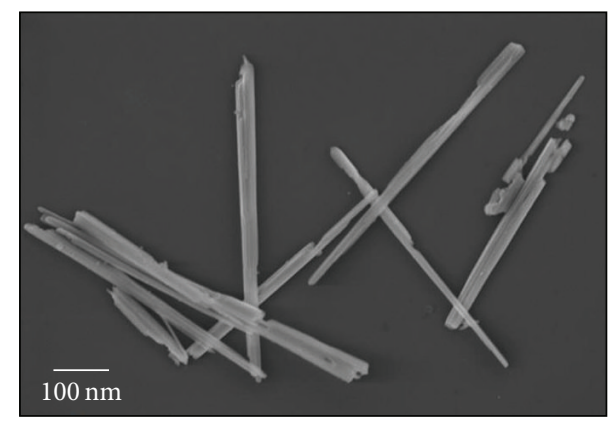

(b)

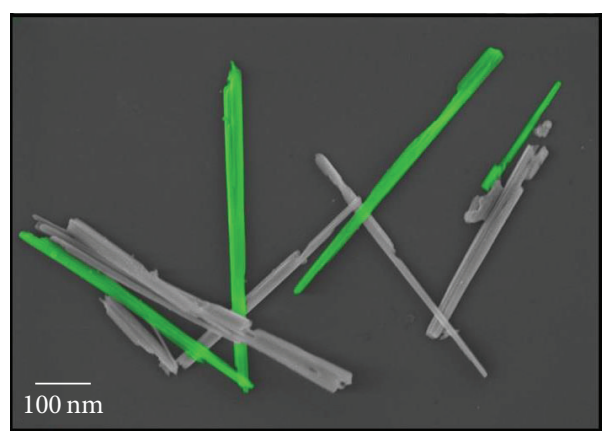

(c)

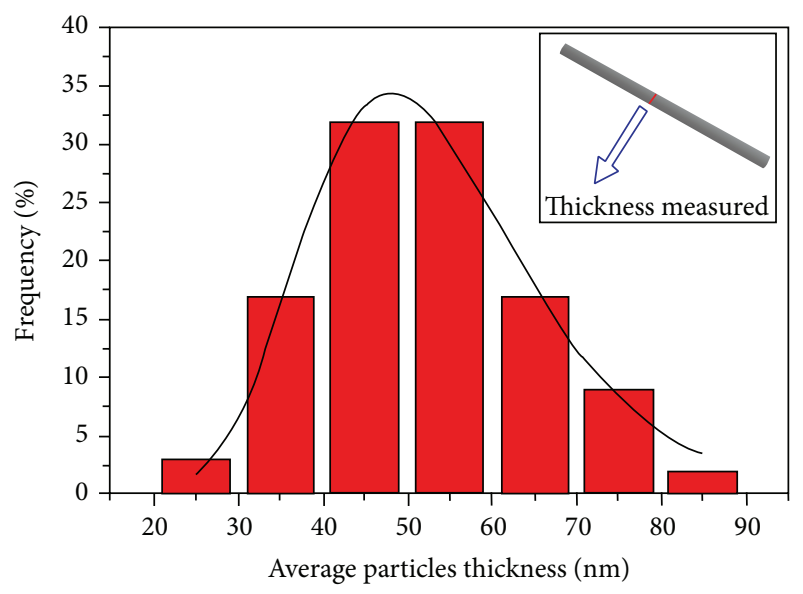

(d)

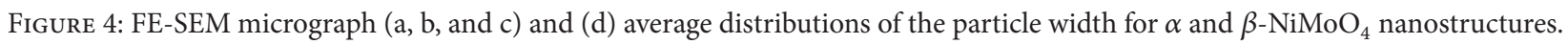

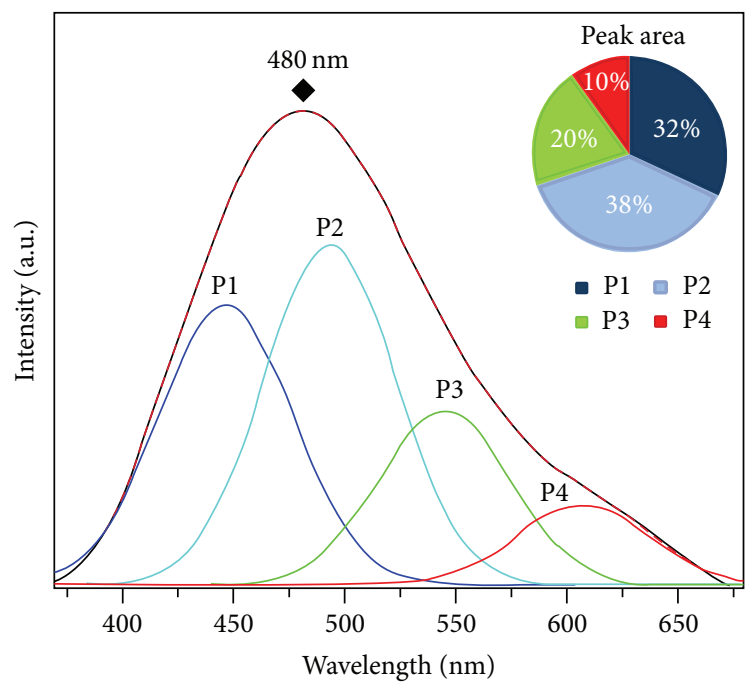

FIGURE 5: PL spectrum at room temperature and its deconvolution spectra of the $\alpha, \beta-\mathrm{NiMoO}_{4}$ nanorods.

levels (deep and shallow defects) within the band gap. In this case, the charge gradient between the clusters generates a polarization in the lattice of $\alpha, \beta-\mathrm{NiMoO}_{4}$ nanorods, can lead to the formation types of distortions on $[\mathrm{O}-\mathrm{Ni}-\mathrm{O}]$ and [O-Mo-O] bonds, and consequently promotes different levels of distortions on the $\left[\mathrm{NiO}_{8}\right],\left[\mathrm{MoO}_{4}\right]$, and $\left[\mathrm{MoO}_{6}\right]$ clusters. These studies have shown that ordered-disordered effects in nano- or microparticles have two types of coordination for $\mathrm{Ni}, \mathrm{Mo}$, or $\mathrm{O}$ atoms into the lattice, and this phenomenon can be related to the local structure at short, medium, and long range distances and favors the formation of complex cluster vacancies that arise from fast crystallization during the initial nucleation process. Based on these structural and electronic order-disorder effects, for the $\alpha, \beta-\mathrm{NiMoO}_{4}$ nanorods, the distortion between these complex clusters causes a polarization and/or difference in charge density in the local structure $[25,46-49]$, which is able to promote a charge transfer from the $\left[\mathrm{NiO}_{8}\right]_{d}^{x} \stackrel{\mathrm{e}^{\prime}}{\rightarrow}\left[\mathrm{NiO}_{8}\right]_{o}^{x},\left[\mathrm{MoO}_{4}\right]_{d}^{x} \stackrel{\mathrm{e}^{\prime}}{\rightarrow}$ $\left[\mathrm{MoO}_{4}\right]_{o}^{x}$, and $\left[\mathrm{MoO}_{6}\right]_{d}^{x} \stackrel{\mathrm{e}^{\prime}}{\rightarrow}\left[\mathrm{MoO}_{6}\right]_{o}^{x}$ complex clusters $(o$ $=$ order and $d=$ disorder). In particular, the cluster-tocluster charge transfer (CCCT) process are a natural consequence due to the presence of the structural defects, which essentially is characterized by excitations involving electronic transitions from one cluster to another cluster [49] and are strongly dependent on the formation and recombination of all complex clusters present in the $\alpha, \beta-\mathrm{NiMoO}_{4}$ crystal was 


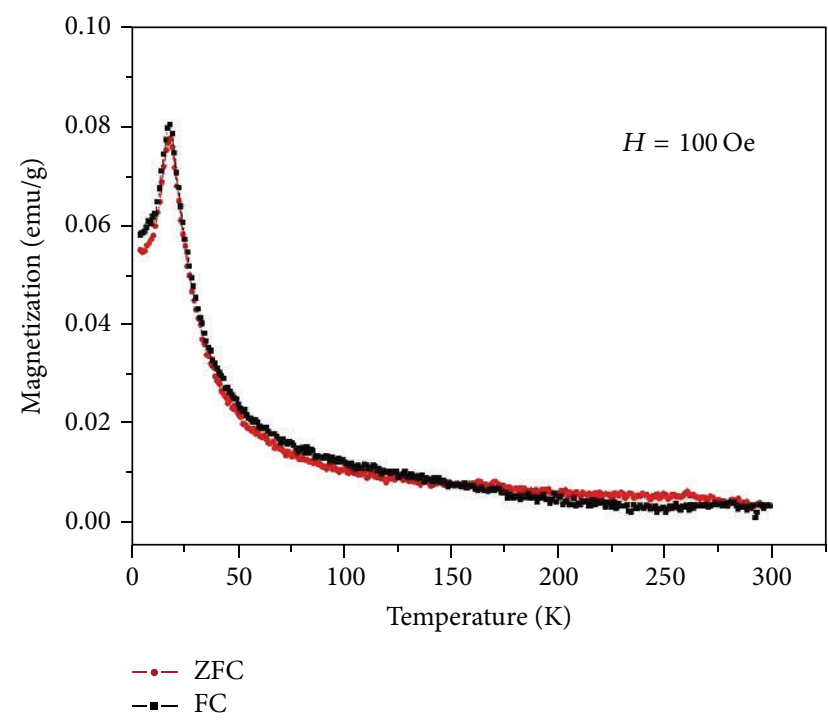

(a)

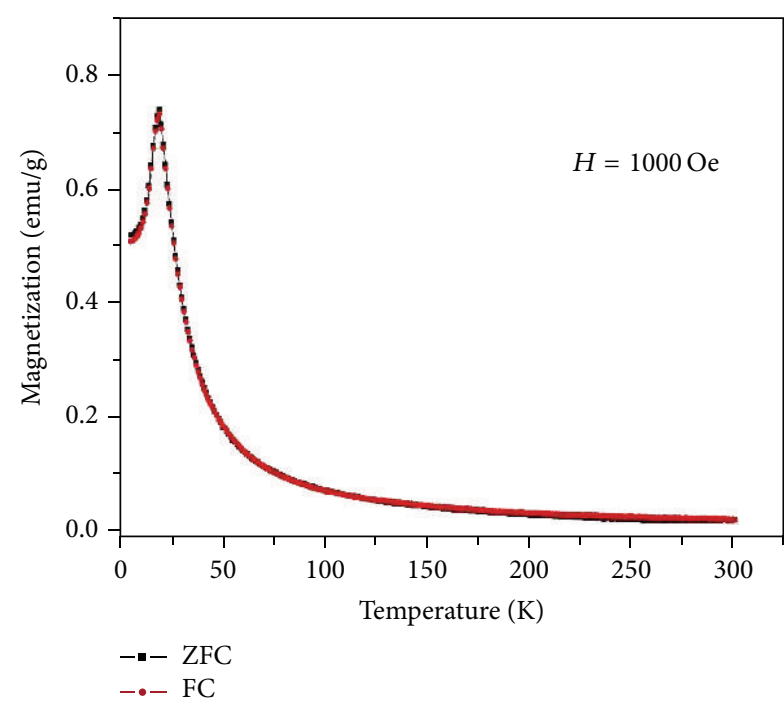

(b)

Figure 6: Temperature dependence of the ZFC and FC magnetizations for $\alpha, \beta-\mathrm{NiMoO}_{4}$ nanorods measured under $100 \mathrm{Oe}$ (a) and $1000 \mathrm{Oe}$ (b) applied fields.

considered and is also represented by Kröger-Vink notation [51] by means of clusters notations in

$$
\begin{aligned}
{\left[\mathrm{NiO}_{8}\right]_{o}^{x}+\left[\mathrm{NiO}_{8}\right]_{d}^{x} } & \longrightarrow\left[\mathrm{NiO}_{8}\right]_{o}^{\prime}+\left[\mathrm{NiO}_{8}\right]_{d}^{\cdot} \\
{\left[\mathrm{MoO}_{4}\right]_{o}^{x}+\left[\mathrm{MoO}_{4}\right]_{d}^{x} } & \longrightarrow\left[\mathrm{MoO}_{4}\right]_{o}^{\prime}+\left[\mathrm{MoO}_{4}\right]_{d}^{\cdot} \\
{\left[\mathrm{MoO}_{6}\right]_{o}^{x}+\left[\mathrm{MoO}_{6}\right]_{d}^{x} } & \longrightarrow\left[\mathrm{MoO}_{6}\right]_{o}^{\prime}+\left[\mathrm{MoO}_{6}\right]_{d}^{\cdot}
\end{aligned}
$$

It is assumed that charge redistribution may lead to electron-hole recombination of localized excitons that result in PL behavior for the $\alpha, \beta-\mathrm{NiMoO}_{4}$ nanorods. Therefore, the structural and electronic reconstructions of all possible combinations of complex clusters belonging to a specific crystal are essential for the deeper understanding of the CCCT process and its influences on the PL phenomenon at the atomic level [49]. In addition, in this study we also investigated the magnetic properties for the $\alpha, \beta-\mathrm{NiMoO}_{4}$ nanorods. Magnetization, as a function of temperature in a range of $2-300 \mathrm{~K}$ for different applied magnetic fields, is shown in Figure 6.

In the "zero-field-cooled" (ZFC) run, the sample was cooled from 300 to $2 \mathrm{~K}$ in the absence of an external applied magnetic field. Then, magnetic field was applied and the magnetization was measured as a function of the temperature in the warming process. Following the ZFC run, in the "fieldcooled" (FC) run, the sample was then cooled from 300 to $2 \mathrm{~K}$ in the presence of an external magnetic field. For both ones, a reversible antiferromagnetic- (AF-) paramagnetic (PM) transition was observed, with an increasing of the magnitude of the magnetization as the magnetic field is increased. The $\alpha, \beta-\mathrm{NiMoO}_{4}$ nanorods present Nèel temperature $\left(T_{N}\right)$ close to $18.5 \mathrm{~K}(H=100 \mathrm{Oe})$ and $17.8 \mathrm{~K}(H=1 \mathrm{kOe})$ in accordance with the literature [52]. Based on our results, we suggest that the structural and electronic order-disorder effects may contribute to the improvement of PL and magnetic properties of $\alpha, \beta-\mathrm{NiMoO}_{4}$ nanorods and are mainly associated with the disorder in the medium-range distance created during the processing of these materials.

\section{Conclusions}

In summary, $\alpha, \beta-\mathrm{NiMoO}_{4}$ nanorods were synthesized by annealing the $\mathrm{NiMoO}_{4}: n \mathrm{H}_{2} \mathrm{O}$ precursor at $600^{\circ} \mathrm{C}$ for $10 \mathrm{~min}$ utes in a domestic microwave. The XRD patterns, FT-Raman, and FTIR spectrum revealed that the nanorods obtained are crystalline structures formed by the $\alpha-\mathrm{NiMoO}_{4}$ and $\beta$ $\mathrm{NiMoO}_{4}$ phases. UV-vis absorption spectroscopy revealed a characteristic optical band gap of $2.2 \mathrm{eV}$, which is associated with the difference of energy between the valence and conduction bands. PL emission at room temperature was verified at $480 \mathrm{~nm}$ (blue emission), which can be attributed to the participation of several energy levels or light emission centers able to trap electrons within the band gap. For both applied magnetic fields a reversible antiferromagnetic-paramagnetic transition was observed.

\section{Conflict of Interests}

The authors declare that there is no conflict of interests regarding the publication of this paper.

\section{Acknowledgments}

The authors gratefully acknowledge the support from the Brazilian agencies FAPESP (2013/07296-2), CNPq (573636/ 2008-7), and CAPES. 


\section{References}

[1] L. S. Cavalcante, V. M. Longo, J. C. Sczancoski et al., "Electronic structure, growth mechanism and photoluminescence of $\mathrm{CaWO}_{4}$ crystals," CrystEngComm, vol. 14, no. 3, pp. 853-868, 2012.

[2] N. B. J. Hetherington, A. N. Kulak, Y.-Y. Kim et al., "Porous single crystals of calcite from colloidal crystal templates: ACC Is not required for nanoscale templating," Advanced Functional Materials, vol. 21, no. 5, pp. 948-954, 2011.

[3] X. Zhang, F. Yan, C. Guo, and G. Yuan, "Preparation of barium sulfate polycrystal from barium peroxide matrix," Materials Letters, vol. 80, pp. 117-120, 2012.

[4] Z. Ma, X. Wei, Y. Chang, S. Xing, and Y. Wu, "Facile synthesis of various manganese oxides nano/micro-crystals by a lignosulfanate-mediated hydrothermal process: effect of the reactant concentration and solution media," Nano, vol. 9, no. 7, Article ID 1450077, 9 pages, 2014.

[5] Y. Li, S. Tan, J. Jiang, Z. Huang, and X. Tan, "Room-temperature synthesis, growth mechanism and properties of uniform $\mathrm{CdMoO}_{4}$ nano-octahedra," CrystEngComm, vol. 13, no. 7, pp. 2649-2655, 2011.

[6] J. A. Rodriguez, S. Chaturvedi, J. C. Hanson, and J. L. Brito, "Reaction of $\mathrm{H}_{2}$ and $\mathrm{H}_{2} \mathrm{~S}$ with $\mathrm{CoMoO}_{4}$ and $\mathrm{NiMoO}_{4}$ : TPR, XANES, time-resolved XRD, and molecular-orbital studies," The Journal of Physical Chemistry B, vol. 103, no. 5, pp. 770-781, 1999.

[7] G. W. Smith and J. A. Ibers, "The crystal structure of cobalt molybdate $\mathrm{CoMoO}_{4}$," Acta Crystallographica, vol. 19, no. 2, pp. 269-275, 1965.

[8] G. W. Smith, "The crystal structures of cobalt molybdate $\mathrm{CoMoO}_{4}$ and nickel molybdate $\mathrm{NiMoO}_{4}$," Acta Crystallographica, vol. 15, pp. 1054-1057, 1962.

[9] A. W. Sleight and B. L. Chamberland, "Transition metal molybdates of the type $\mathrm{AMoO}_{4}$," Inorganic Chemistry, vol. 7, no. 8, pp. 1672-1675, 1968.

[10] J. A. Rodriguez, S. Chaturvedi, J. C. Hanson, A. Albornoz, and J. L. Brito, "Electronic properties and phase transformations in $\mathrm{CoMoO}_{4}$ and $\mathrm{NiMoO}_{4}$ : XANES and time-resolved synchrotron XRD studies," Journal of Physical Chemistry B, vol. 102, no. 8, pp. 1347-1355, 1998.

[11] H. Wan, J. Jiang, X. Ji et al., "Rapid microwave-assisted synthesis $\mathrm{NiMoO}_{4} \cdot \mathrm{H}_{2} \mathrm{O}$ nanoclusters for supercapacitors," Materials Letters, vol. 108, pp. 164-167, 2013.

[12] S. Chaturvedi, J. A. Rodriguez, and J. L. Brito, "Characterization of pure and sulfided $\mathrm{NiMoO}_{4}$ catalysts using synchrotronbased X-ray absorption spectroscopy (XAS) and temperatureprogrammed reduction (TPR)," Catalysis Letters, vol. 51, no. 3-4, pp. 85-93, 1998.

[13] J. L. Brito and A. L. Barbosa, "Effect of phase composition of the oxidic precursor on the HDS activity of the sulfided molybdates of Fe(II), Co(II), and Ni(II)," Journal of Catalysis, vol. 171, no. 2, pp. 467-475, 1997.

[14] C. Mazzocchia, C. Aboumrad, C. Diagne, E. Tempesti, J. M. Herrmann, and G. Thomas, "On the $\mathrm{NiMoO}_{4}$ oxidative dehydrogenation of propane to propene: some physical correlations with the catalytic activity," Catalysis Letters, vol. 10, no. 3-4, pp. 181-191, 1991.

[15] B. Moreno, E. Chinarro, M. T. Colomer, and J. R. Jurado, "Combustion synthesis and electrical behavior of nanometric $\beta$ $\mathrm{NiMoO}_{4}$," The Journal of Physical Chemistry $C$, vol. 114, no. 10, pp. 4251-4257, 2010.
[16] F. A. la Porta, J. Andrés, M. S. Li, J. R. Sambrano, J. A. Varela, and E. Longo, "Zinc blende versus wurtzite $\mathrm{ZnS}$ nanoparticles: control of the phase and optical properties by tetrabutylammonium hydroxide," Physical Chemistry Chemical Physics, vol. 16, no. 37, pp. 20127-20137, 2014.

[17] F. A. La Porta, M. M. Ferrer, Y. V. B. de Santana et al., "Synthesis of wurtzite $\mathrm{ZnS}$ nanoparticles using the microwave assisted solvothermal method," Journal of Alloys and Compounds, vol. 556, pp. 153-159, 2013.

[18] C. Burda, X. Chen, R. Narayanan, and M. A. El-Sayed, "Chemistry and properties of nanocrystals of different shapes," Chemical Reviews, vol. 105, no. 4, pp. 1025-1102, 2005.

[19] H. Wan, J. Jiang, X. Ji et al., "Rapid microwave-assisted synthesis $\mathrm{NiMoO}_{4}-\mathrm{H}_{2} \mathrm{O}$ nanoclusters for supercapacitors," Materials Letters, vol. 108, pp. 164-167, 2013.

[20] F. V. Motta, R. C. Lima, A. P. A. Marques, E. R. Leite, J. A. Varela, and E. Longo, " $\mathrm{In}_{2} \mathrm{O}_{3}$ microcrystals obtained from rapid calcination in domestic microwave oven," Materials Research Bulletin, vol. 45, no. 11, pp. 1703-1706, 2010.

[21] D. Keyson, D. P. Volanti, L. S. Cavalcante et al., "Domestic microwave oven adapted for fast heat treatment of $\mathrm{Ba}_{0.5} \mathrm{Sr}_{0.5}\left(\mathrm{Ti}_{0.8} \mathrm{Sn}_{0.2}\right) \mathrm{O}_{3}$ powders," Journal of Materials Processing Technology, vol. 189, no. 1-3, pp. 316-319, 2007.

[22] A. Z. Simões, M. A. Ramirez, C. S. Riccardi, E. Longo, and J. A. Varela, "Effect of the microwave oven on structural, morphological and electrical properties of $\mathrm{SrBi}_{4} \mathrm{Ti}_{4} \mathrm{O}_{15}$ thin films grown on $\mathrm{Pt} / \mathrm{Ti} / \mathrm{SiO}_{2} / \mathrm{Si}$ substrates by a soft chemical method," Materials Characterization, vol. 59, no. 6, pp. 675-680, 2008.

[23] H. Katsuki, N. Kamochi, and S. Komarneni, "Novel energysaving materials for microwave heating," Chemistry of Materials, vol. 20, no. 15, pp. 4803-4807, 2008.

[24] J. P. Cheng, D. K. Agrawal, S. Komarneni, M. Mathis, and R. Roy, "Microwave processing of WC-Co composities and ferroic titanates," Materials Research Innovations, vol. 1, no. 1, pp. 44-52, 1997.

[25] A. P. de Moura, R. C. Lima, E. C. Paris, M. S. Li, J. A. Varela, and E. Longo, "Formation of $\beta$-nickel hydroxide plate-like structures under mild conditions and their optical properties," Journal of Solid State Chemistry, vol. 184, no. 10, pp. 2818-2823, 2011.

[26] A. P. de Moura, L. H. de Oliveira, E. C. Paris et al., "Photolumiscent properties of nanorods and nanoplates $\mathrm{Y}_{2} \mathrm{O}_{3}$ : $\mathrm{Eu}^{3+}$," Journal of Fluorescence, vol. 21, no. 4, pp. 1431-1438, 2011.

[27] A. P. de Moura, L. H. de Oliveira, P. F. S. Pereira et al., "Photoluminescent properties of $\mathrm{CoMoO}_{4}$ nanorods quickly synthesized and annealed in a domestic microwave oven," Advances in Chemical Engineering and Science, vol. 2, no. 4, pp. 465-473, 2012.

[28] G. Gasparotto, M. A. N. Bordignon, C. R. Foschini, E. C. Aguiar, M. A. Zaguete, and L. Perazolli, " $\mathrm{SnO}_{2}$ ceramics with low electrical resistivity obtained by microwave sintering," Journal of Advanced Microscopy Research, vol. 6, no. 3, pp. 193-200, 2011.

[29] E. C. Aguiar, A. Z. Simões, E. Longo, and J. A. Varela, "Influence of microwave energy on structural and piezoelectric response of $\mathrm{Bi}_{4} \mathrm{Ti}_{3} \mathrm{O}_{12}$ ceramics," Journal of Advanced Microscopy Research, vol. 5, no. 3, pp. 209-216, 2010.

[30] M. Oghbaei and O. Mirzaee, "Microwave versus conventional sintering: a review of fundamentals, advantages and applications," Journal of Alloys and Compounds, vol. 494, no. 1-2, pp. 175-189, 2010. 
[31] H. M. Rietveld, "A profile refinement method for nuclear and magnetic structures," Journal of Applied Crystallography, vol. 2, pp. 65-71, 1969.

[32] A. le Bail, H. Duroy, and J. L. Fourquet, "Ab-initio structure determination of $\mathrm{LiSbWO}_{6}$ by X-ray powder diffraction," Materials Research Bulletin, vol. 23, no. 3, pp. 447-452, 1988.

[33] A. C. Larson and R. B. Von Dreele, General Structure Analysis System (GSAS), vol. 86, Los Alamos National Laboratory Report LAUR, 1994.

[34] Y. Ding, Y. Wan, Y.-L. Min, W. Zhang, and S.-H. Yu, "General synthesis and phase control of metal molybdate hydrates $\mathrm{MMoO}_{4} \cdot \mathrm{nH}_{2} \mathrm{O}(\mathrm{M}=\mathrm{Co}, \mathrm{Ni}, \mathrm{Mn}, n=0,3 / 4,1)$ nano/ microcrystals by a hydrothermal approach: magnetic, photocatalytic, and electrochemical properties," Inorganic Chemistry, vol. 47, no. 17, pp. 7813-7823, 2008.

[35] J. Haetge, I. Djerdj, and T. Brezesinski, "Nanocrystalline $\mathrm{NiMoO}_{4}$ with an ordered mesoporous morphology as potential material for rechargeable thin film lithium batteries," Chemical Communications, vol. 48, no. 53, pp. 6726-6728, 2012.

[36] R. Zǎvoianu, C. R. Dias, A. P. V. Soares, and M. F. Portela, "Oxidative dehydrogenation of i-butane over nanostructured silica-supported $\mathrm{NiMoO}_{4}$ catalysts with low content of active phase," Applied Catalysis A: General, vol. 298, no. 1-2, pp. 40-49, 2006.

[37] C. Mazzocchia, C. Aboumrad, C. Diagne, E. Tempesti, J. M. Herrmann, and G. Thomas, "On the $\mathrm{NiMoO}_{4}$ oxidative dehydrogenation of propane to propene: some physical correlations with the catalytic activity," Catalysis Letters, vol. 10, no. 3-4, pp. 181-191, 1991.

[38] N. V. Y. Scarlett and I. C. Madsen, "Quantification of phases with partial or no known crystal structures," Powder Diffraction, vol. 21, no. 4, pp. 278-284, 2006.

[39] F. Trivinho-Strixino, D. X. da Silva, C. O. Paiva-Santos, and E. C. Pereira, "Tetragonal to monoclinic phase transition observed during Zr anodisation," Journal of Solid State Electrochemistry, vol. 17, no. 1, pp. 191-199, 2013.

[40] H. M. Abdel-Dayem, "Dynamic phenomena during reduction of $\alpha-\mathrm{NiMoO}_{4}$ in different atmospheres: in-situ thermoraman spectroscopy study," Industrial and Engineering Chemistry Research, vol. 46, no. 8, pp. 2466-2472, 2007.

[41] J. Y. Zou and G. L. Schrader, "Deposition of multiphase molybdate thin films by reactive sputtering," Thin Solid Films, vol. 324, no. 1-2, pp. 52-62, 1998.

[42] E. Roduner, "Size matters: why nanomaterials are different," Chemical Society Reviews, vol. 35, no. 7, pp. 583-592, 2006.

[43] A. P. Alivisatos, "Perspectives on the physical chemistry of semiconductor nanocrystals," The Journal of Physical Chemistry, vol. 100, no. 31, pp. 13226-13239, 1996.

[44] A. M. Smith, A. M. Mohs, and S. Nie, "Tuning the optical and electronic properties of colloidal nanocrystals by lattice strain," Nature Nanotechnology, vol. 4, no. 1, pp. 56-63, 2009.

[45] P. K. Pandey, N. S. Bhave, and R. B. Kharat, "Preparation and characterization of spray deposited $\mathrm{NiMoO}_{4}$ thin films for photovoltaic electrochemical studies," Materials Research Bulletin, vol. 41, no. 6, pp. 1160-1169, 2006.

[46] I. C. Nogueira, L. S. Cavalcante, P. F. S. Pereira et al., "Rietveld refinement, morphology and optical properties of $\left(\mathrm{Ba}_{1-x} \mathrm{Sr}_{x}\right) \mathrm{MoO}_{4}$ crystals," Journal of Applied Crystallography, vol. 46, no. 5, pp. 1434-1446, 2013.

[47] J. C. Sezancoski, M. D. R. Bomio, L. S. Cavalcante et al., "Morphology and blue photoluminescence emission of $\mathrm{PbMoO}_{4}$ processed in conventional hydrothermal," The Journal of Physical Chemistry C, vol. 113, no. 14, pp. 5812-5822, 2009.

[48] V. S. Marques, L. S. Cavalcante, J. C. Sczancoski et al., "Effect of different solvent ratios (water/ethylene glycol) on the growth process of $\mathrm{CaMoO}_{4}$ crystals and their optical properties," Crystal Growth \& Design, vol. 10, no. 11, pp. 4752-4768, 2010.

[49] V. M. Longo, L. S. Cavalcante, E. C. Paris et al., "Hierarchical assembly of $\mathrm{CaMoO}_{4}$ nano-octahedrons and their photoluminescence properties," The Journal of Physical Chemistry C, vol. 115, no. 13, pp. 5207-5219, 2011.

[50] http://www.systat.com/products/PeakFit/.

[51] F. A. Kroger and H. J. Vink, in Solid State Physics, F. Seitz and D. Turnbull, Eds., p. 307, Academic Press, New York, NY, USA, 3rd edition, 1956.

[52] H. Ehrenberg, M. Wiesmann, H. Paulus, and H. Weitzel, "Magnetic phase diagrams of $\alpha-\mathrm{NiMoO}_{4}$," Journal of Magnetism and Magnetic Materials, vol. 186, no. 1-2, pp. 74-80, 1998. 

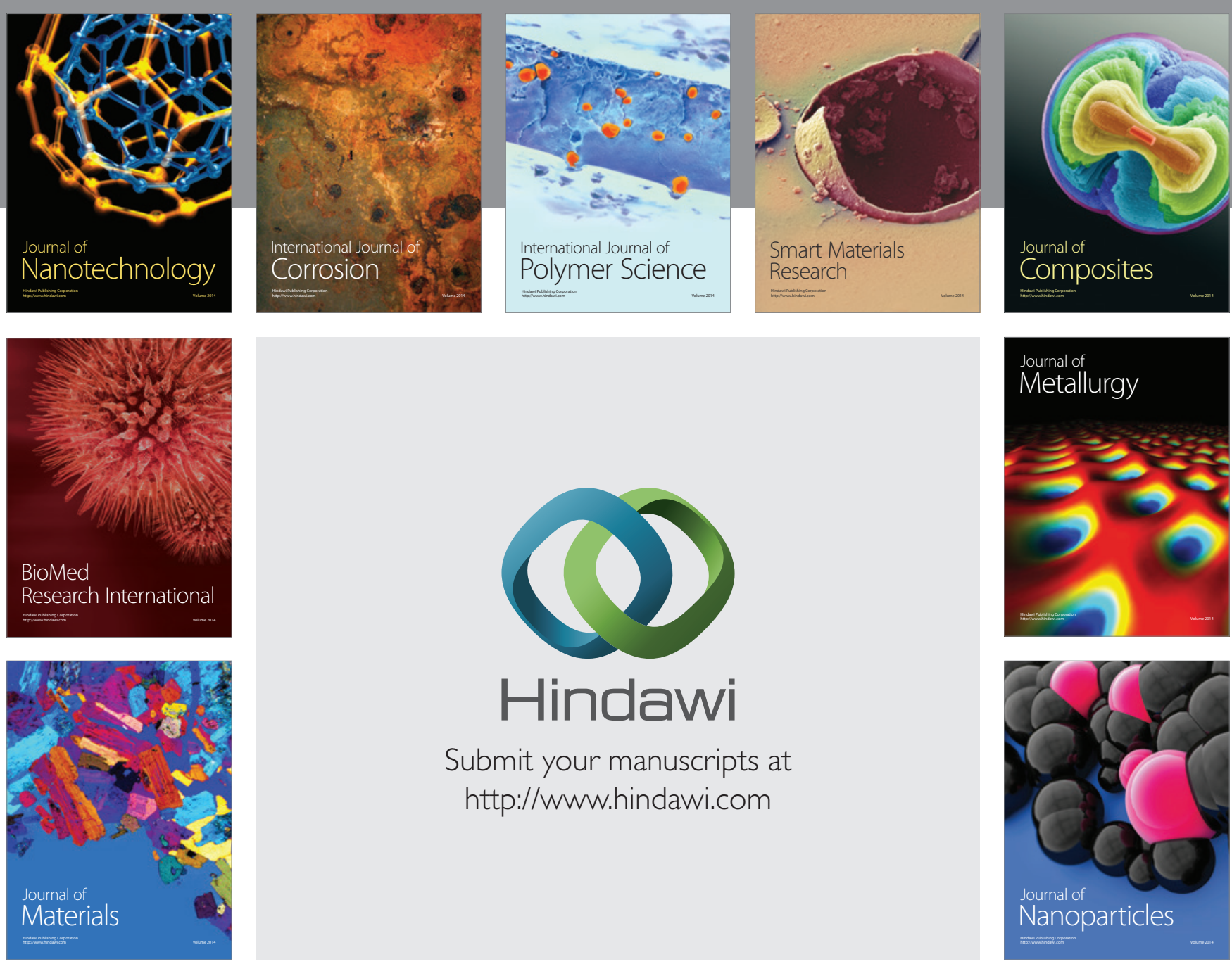

Submit your manuscripts at http://www.hindawi.com
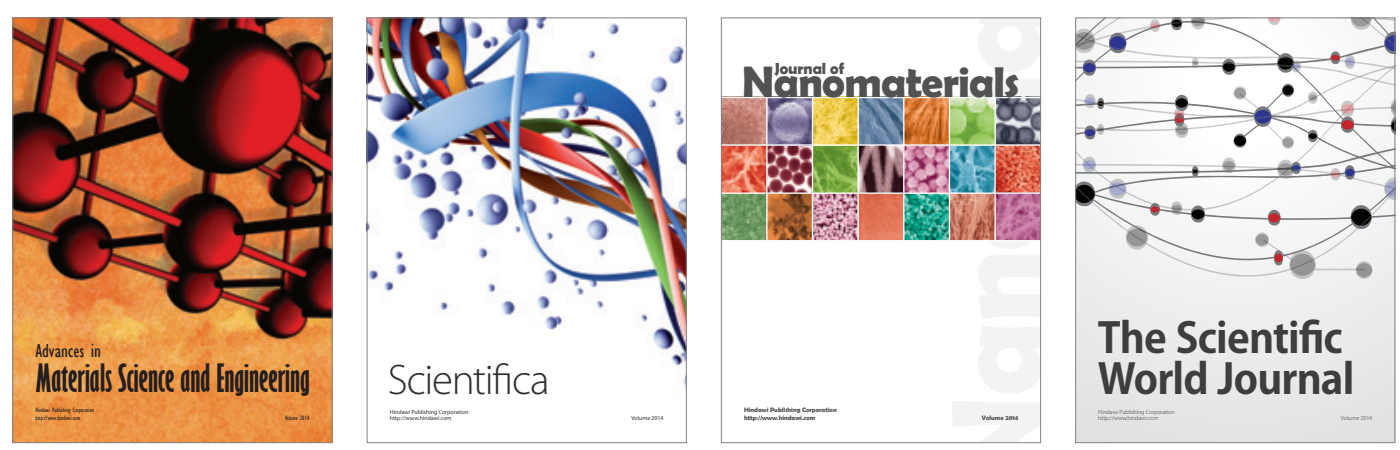

\section{The Scientific World Journal}
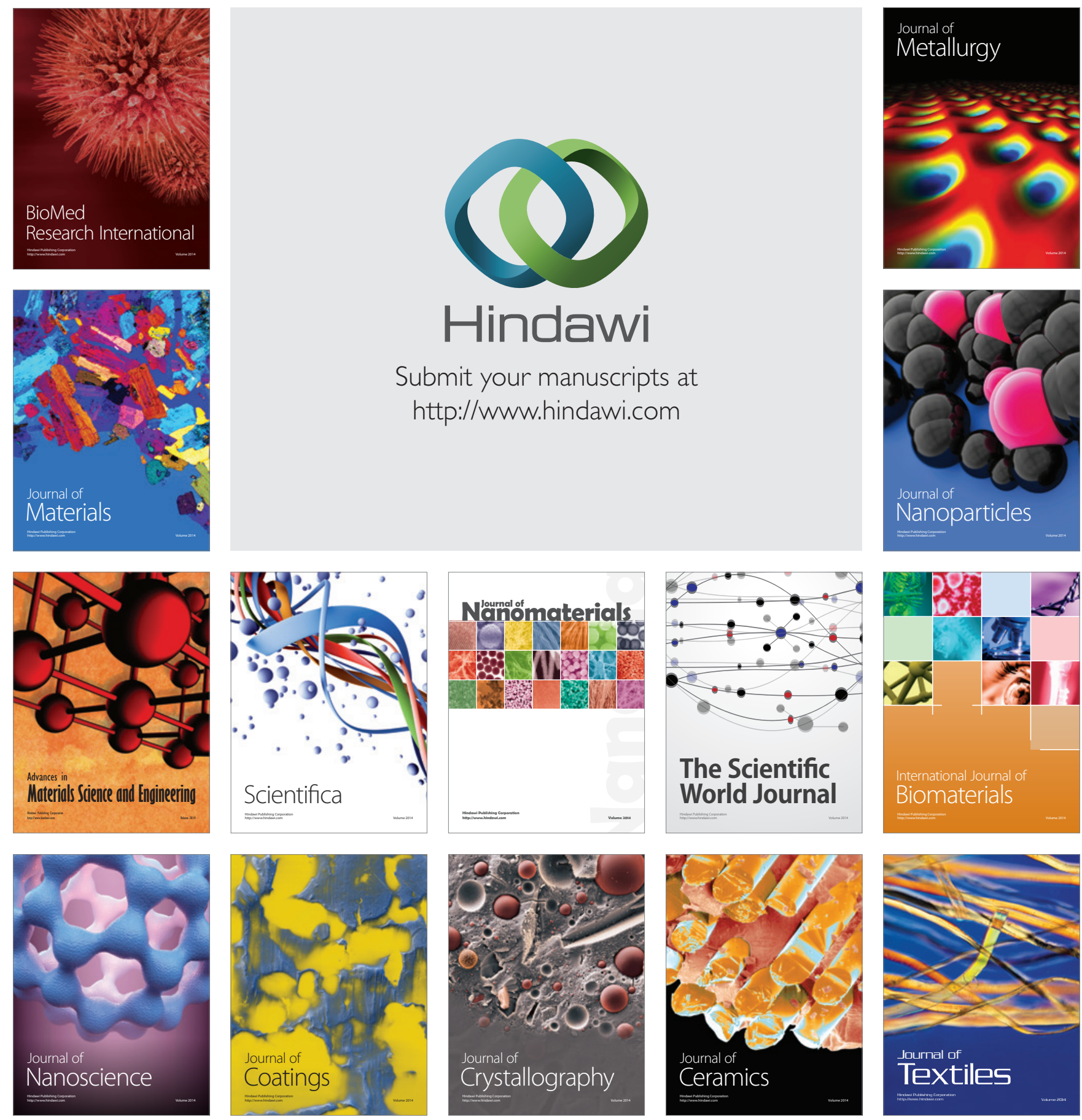